\title{
The Relationship between the Organizational Conflict and the Depression in the Faculty Members of Hamadan University of Medical Sciences in 1396
}

\author{
Yadollah Hamidi ${ }^{1}$, Farshid Shamsaei ${ }^{2}$, Mahdi Beglari ${ }^{3 *}$, Zahra Toosi ${ }^{4}$, Maryam Farhadian ${ }^{5}$
}

1. Associate Professor, Social Determinants of Health Research Center, Department of Health Management and Economics, School of Public Health, Hamadan University of Medical Sciences, Hamadan, Iran

2. Associate Professor, Department of Nursing, Faculty of Nursing and Midwifery, Hamadan University of Medical Sciences, Hamadan, Iran

3. MSc, Department of Health Management, School of Public Health, Hamadan University of Medical Sciences, Hamadan, Iran

4. MSc, Department of Health Management, School of Public Health, Hamadan University of Medical Sciences, Hamadan, Iran

5. Assistant Professor, Department of Biostatistics, School of public Health, Hamadan University of Medical Science, Hamadan, Iran

\section{Article Info \\ Original Article \\ Received: 15 Oct. 2017; \\ Accepted: 16 Jan. 2018; \\ Published Online 2018/01/23 \\ DOI: $10.30699 /$ jergon.5.3.29}

Use your device to scan and read the article online

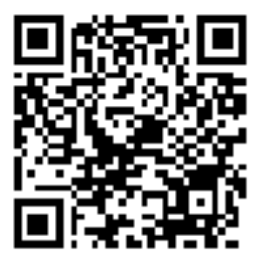

Corresponding Author Mahdi Beglari

MSc, Department of Health

Management, School of

Public Health, Hamadan

University of Medical

Sciences, Hamadan, Iran

Tel: 09188131169 Email:

mahdibeglari@yahoo.com

\section{ABSTRACT}

Background: Focusing on the organizational conflict and the depression in the main trainers of an educational system, the faculty members are very necessary because the increased negative organizational conflicts lead to a lower public health. Therefore, the aim of this study was to investigate the relationship between the job depression and the organizational conflict in the faculty members.

Methods: The present study was a correlation type research and the statistical population included seven faculty members of the department/school/institute of medical sciences in the city of Hamedan with 244 faculty members as per the census of 2017. For the collection of the data, the Goldberg and Hiller questionnaire was used for measuring the depression and the organizational conflict inventory. Using descriptive statistics such as Pearson's correlation coefficient and regression analysis, the data were analyzed for modeling by the SPSS Statistics 24 software.

Results: The mean scores of the depression, the organizational conflict, the conflict with the manager, the similar degrees, and the control were $0.8,22,6.7,7.4$, and 7.9 respectively. The results showed a significant and positive correlation between the depression and the organizational conflict $(P=0.001, r=0.42)$. Such correlations were also observed in the two dimensions of conflict with the others $(P=0.001, \mathrm{r}=0.62)$ and conflict with the control $(\mathrm{P}=0.001, \mathrm{r}=0.43)$. However, no significant correlation was observed in the dimension of conflict with the manager.

Conclusion: The different factors of conflict studied in the society must be focused on, addressed, and improved in light of the positive and direct correlations observed between the organizational conflict and the job depression.

Keywords: Depression; Organizational Conflict; Faculty

Copyright $\odot$ (2018, Journal of Ergonomics. This is an open-access article distributed under the terms of the Creative Commons Attribution-noncommercial 4.0 International License which permits copy and redistribute the material just in noncommercial usages, provided the original work is properly cited.

\section{How to Cite This Article:}

Hamidi Y, Shamsaei F, Beglari M, Toosi Z, Farhadian M. The Relationship between the Organizational Conflict and the Depression in the Faculty Members of Hamadan University of Medical Sciences in 1396. J Ergon. 2018; 5 (3) :29-35 


\section{مقاله يثروهشى}

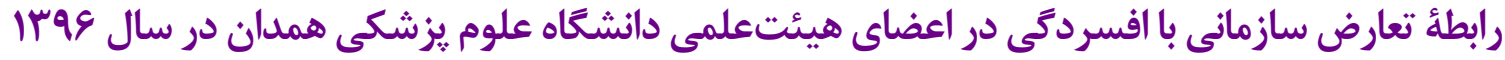

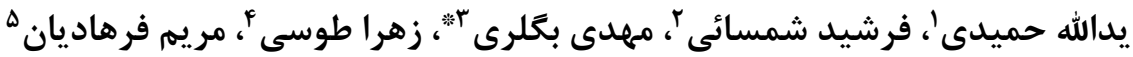

ا. دانشيار، مركز تحقيقات عوامل اجتماعى موثر بر سلامت، گروه مديريت و اقتصاد، دانشكده بهداشت، دانشكاه علوم يزشكى همدان،

همدان، ايران

r. دانشيار، دانشكدة يُرستارى، دانشخاه علوم يزشكى همدان، همدان، ايران

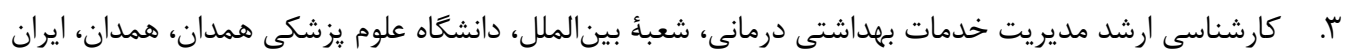

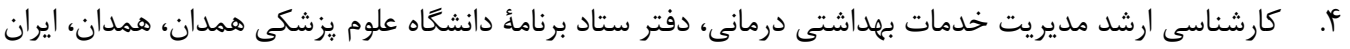

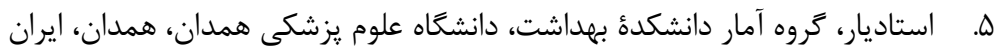

\begin{tabular}{|c|c|}
\hline خلاصه & اطلاعات مقاله \\
\hline 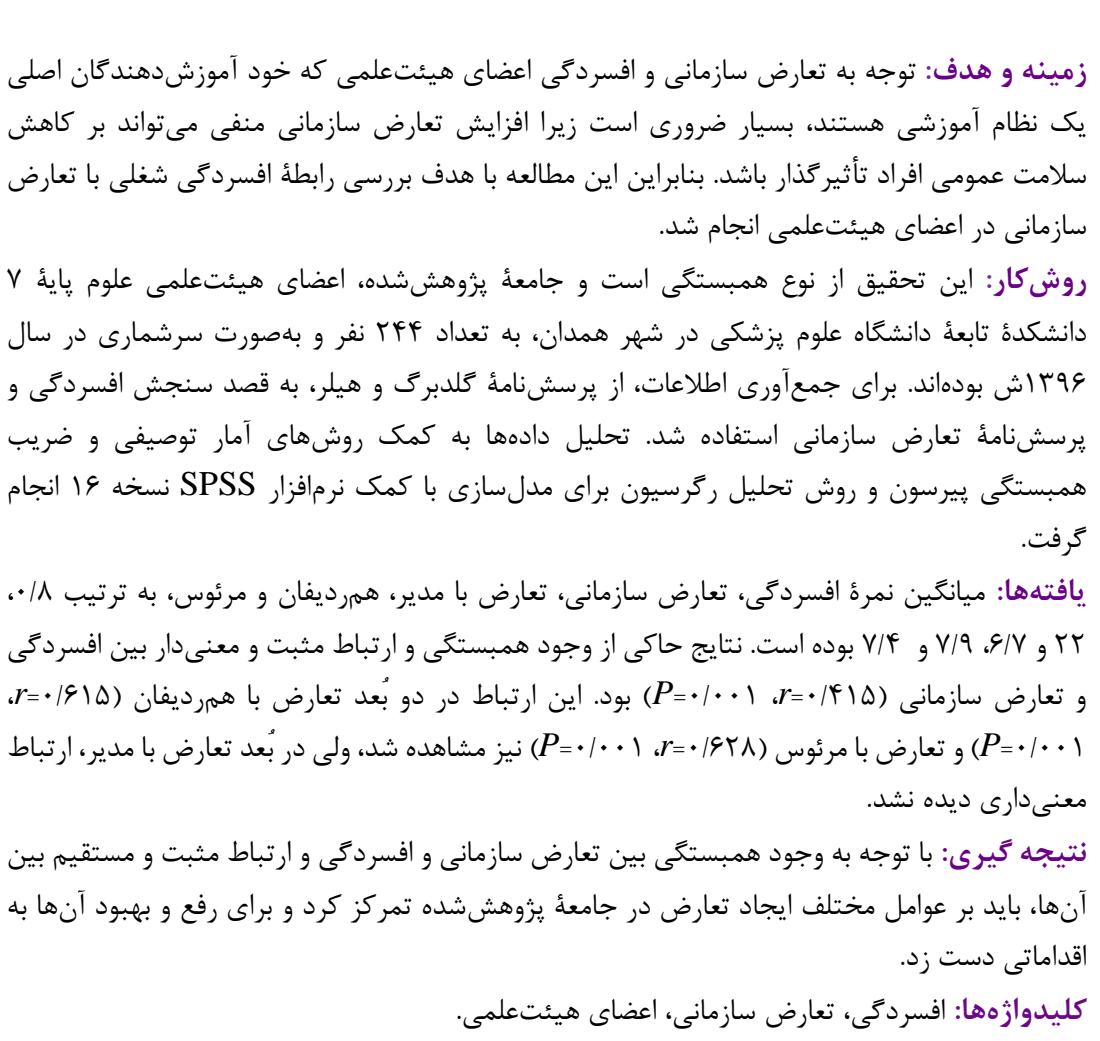 & 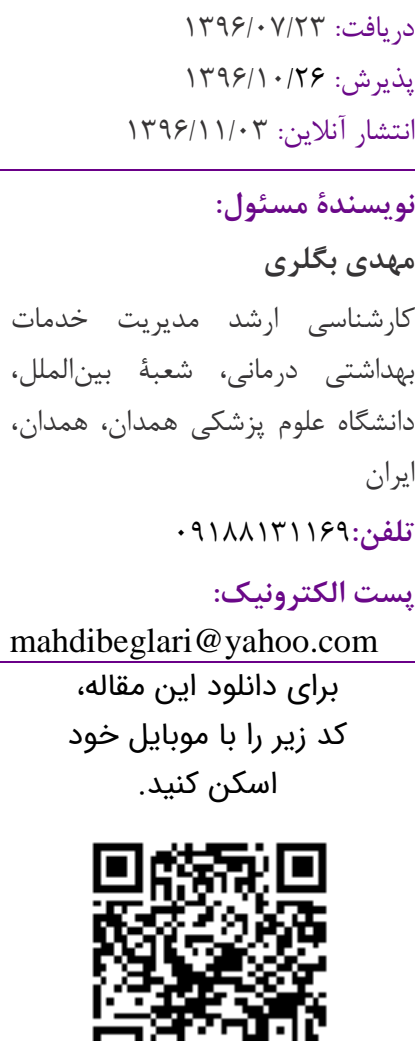 \\
\hline
\end{tabular}

مقدمه

بنابراين سلامت عمومى اين افراد ضرورى است زيرا كاهش سلامت عمومى باعث افزايش فرسودگى شغلى و درنتيجه اين إنى كاهش عملكرد سازمانى مىشود [ب]. به اعتقاد كارشناسان، هماكنون نشانههاى صريحى از افسردگى، عواطف منفى و و

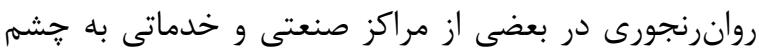

اعضاى هيئتعلمى دانشخاهها، يكى از اساسىترين مؤلفهها در خدمات آموزشى - يروهشى كشورها و الخوى علمى دانشجويان هستند و ييشرفت علمى كشور تا حد زيادى بدانها وابسته است. در محيطى كه استادان افسرده هستند،

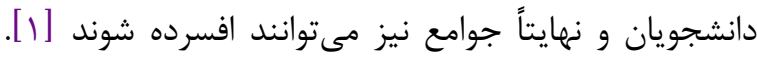


اتفاق نيفتد، فىنفسه وجود نخواهد داشت [ [ []. بر بايئ نظريأ

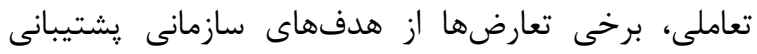

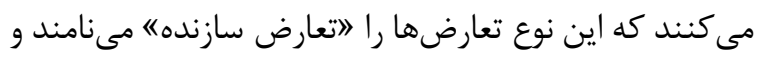

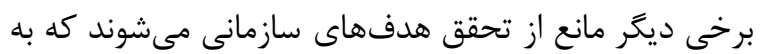

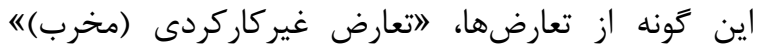

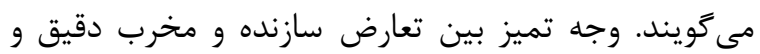

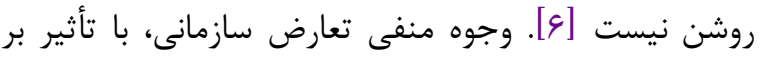

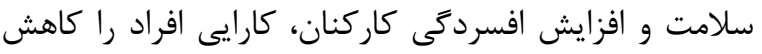

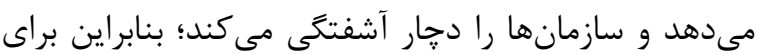

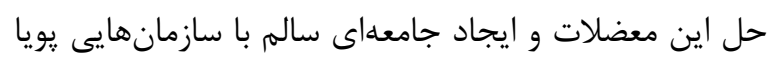

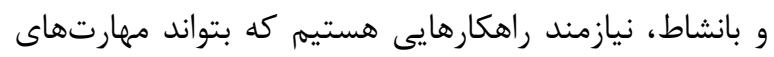

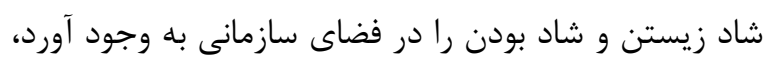

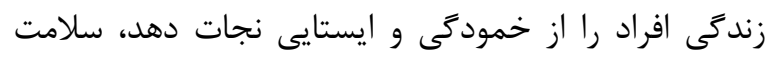

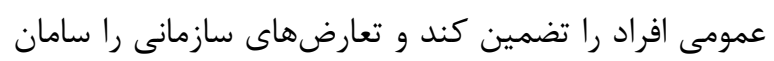

بخشد.

ازآنجاكه تعارض سازمانى مىتواند تأثير بسزايى بر سلامت

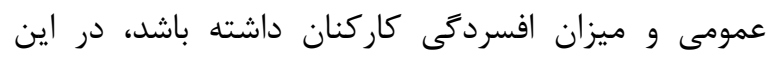

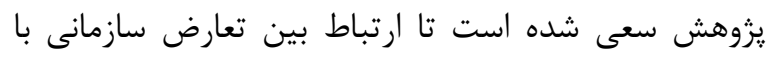
افسردىى اعضاى هيئتعلمى در دانشخاه علوم يزشكى همدان

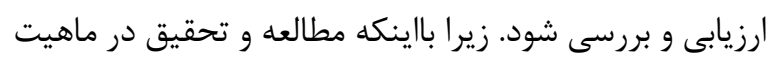

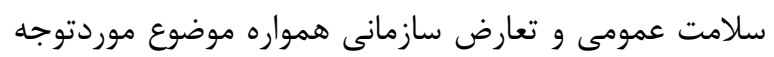
يزوهشكران و صاحبنظران مشهور اين حوزه بوده؛ ولى تاكنون

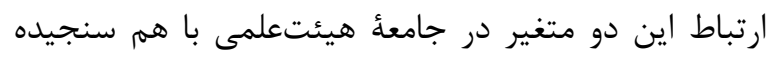

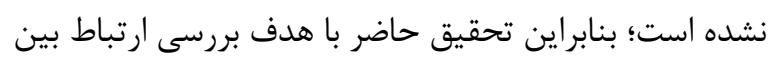
تعارض سازمانى با افسردگى در اعضاى هيئتعلمى دانشعاه علوم يزشكى در شهر همدان انجام شده است.

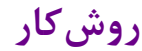

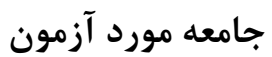

اين تحقيق از نوع همبستكى و كاربردى است كه در سال

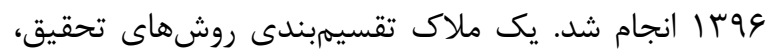

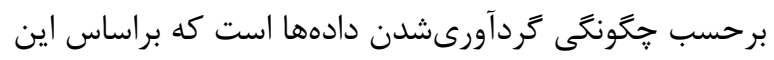

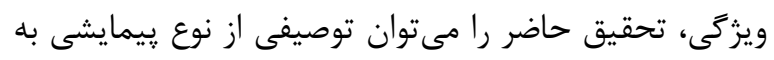

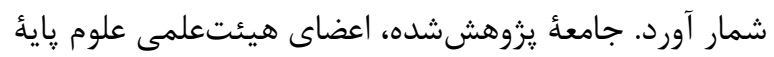
V دانشكدة تابعة دانشكاه علوم يزشكى همدان مستقر در شهر

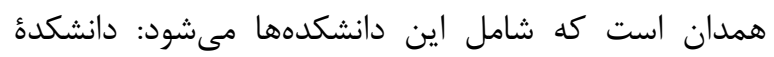

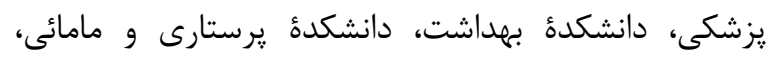

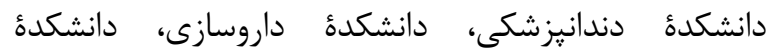

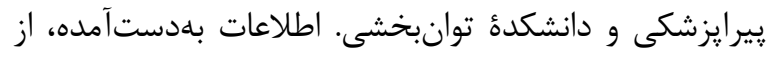

مىخورد كه ييامدهايى نظير קائين آمدن راندمان كارى،

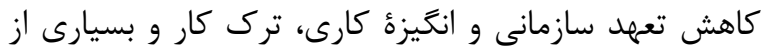

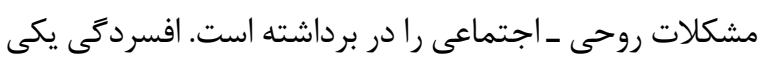
از ابعاد سلامت عمومى است كه نشانههايى از شيوع روزافزون

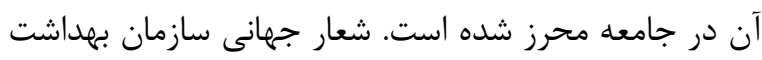

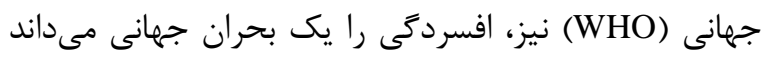

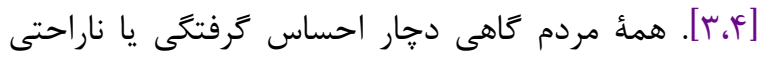

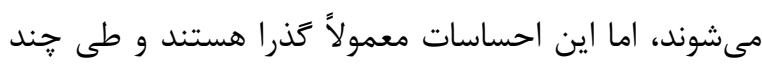

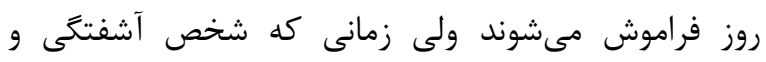

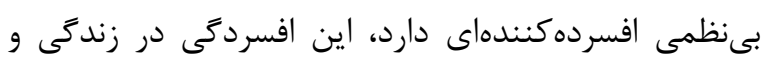

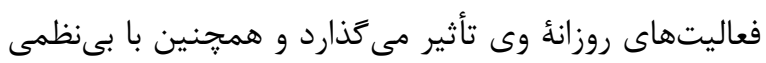

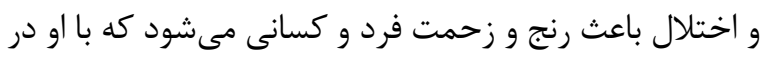

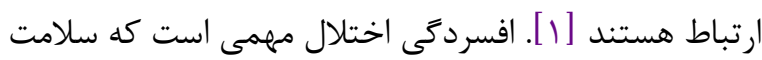

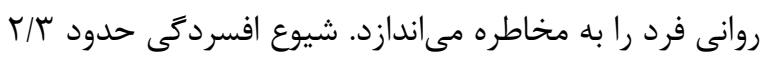

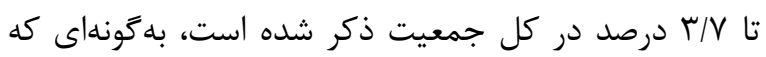

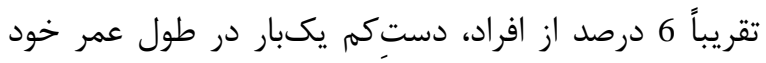

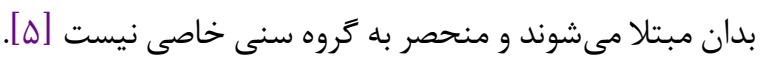

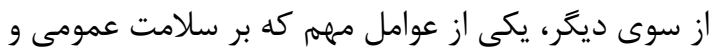

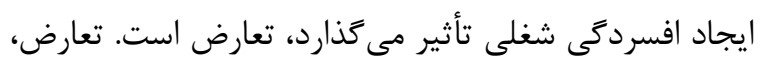

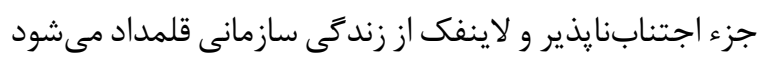

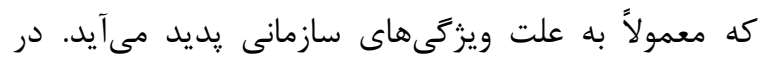

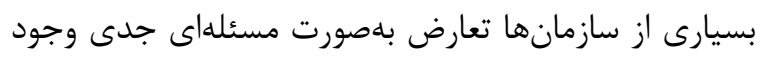

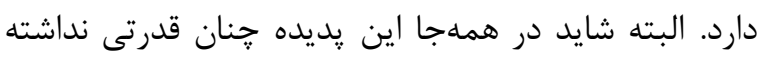

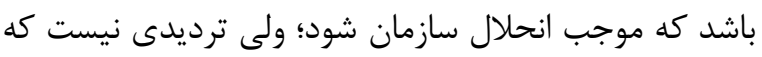

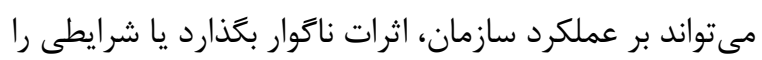

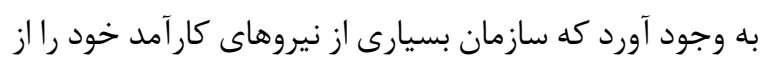

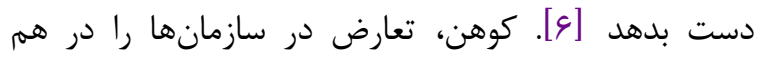

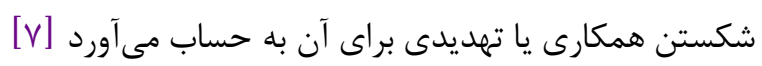

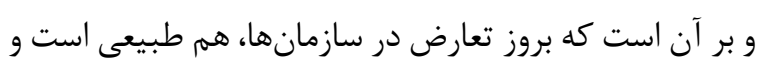

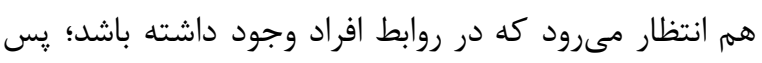

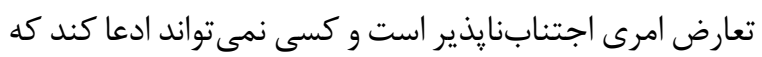

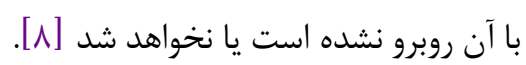

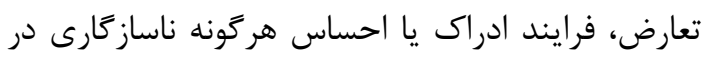

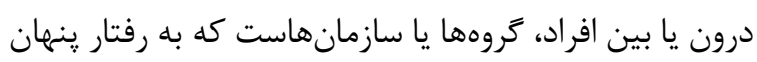

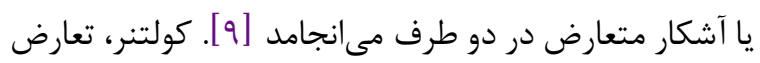

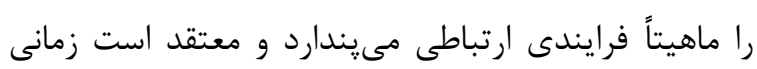

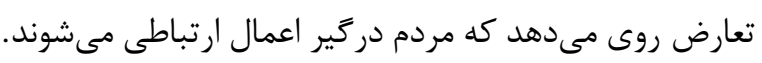

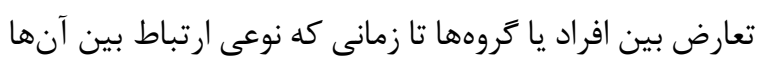


هيئتعلمى در اتاق خود حضور داشتند، بين آنها توزيع و

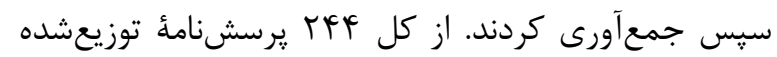

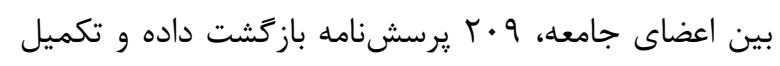

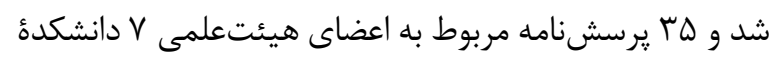
مطالعهشده، به دليل تكميل نكردن يرسشنامه طى مراجعات

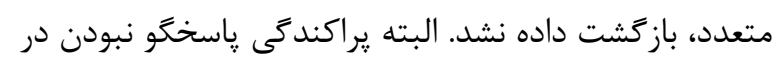
كل دانشكدهها يكسان بود.

\section{بررسى و تحليل دادهها}

تحليل دادهها به كمك روشهاى آمار توصيفى و آزمون

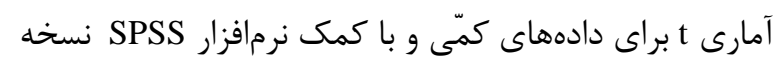

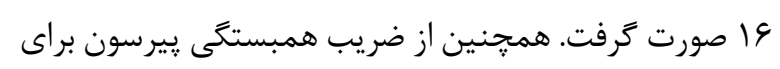
تعيين ميزان همبستكى متغيرهاى مطالعهشده و روش تحليل ركرسيون براى مدلسازى استفاده شد.

\section{بافته ها}

اطلاعات دموگرافيك جامعd يزوهششده برحسب

$$
\text { متغيرهاى كيفى در جدول شماره ا آمده است. }
$$

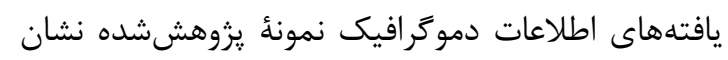

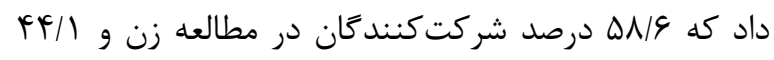

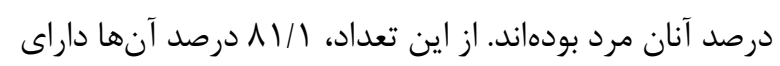
مدرى دكترى بودند و باقى مدرى فوقليسانس داشتند.

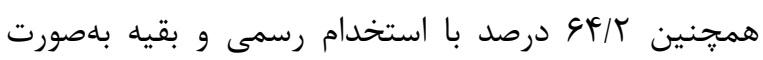
رسمى آزمايشى، قرادادى و ي يمانى مشغول به خدمت بودند. توزيع ميانگين تعارض سازمانى برحسب هر يكى يك از إبعاد

$$
\text { آن در جدول شماره ب آمده است. }
$$

براساس نتايج جدول شماره rا، ميانگين تعارض سازمانى

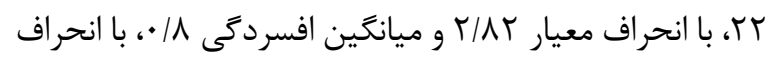
معيار NDD/ • بوده است. تعارض با همرديفان نمره ميانخين بالاتر و تعارض با مدير نمرهٔ ميانخين پائينترى داشت.
همة اعضاى هيئتعلمى علوم يايه يعنى از FFF تن، بهصورت

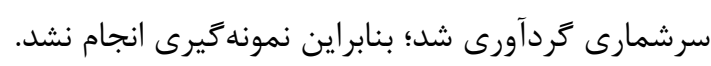

روايى و هايايى :برسشنامه

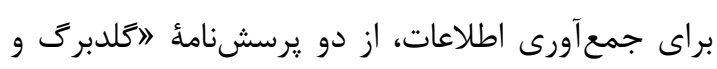

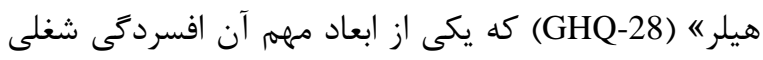

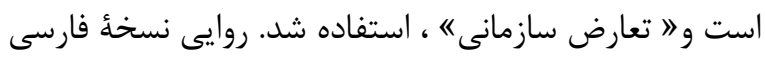

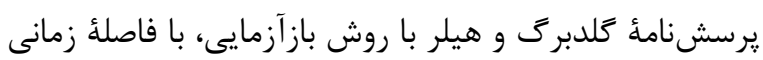

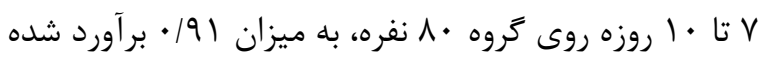

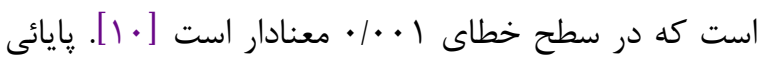
اين يرسشنامه با استفاده از روش آلفاى كرونباخ برابر |N| | محاسبه شد.

\section{سنجش تعارض سازمانى}

براى سنجش تعارض سازمانى، با استفاده از يرسشنامئ 9

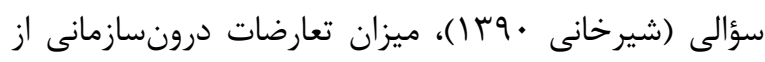
سه بُعد تعارض مرئوس، تعارض با مدير و تعارض با همرديفان

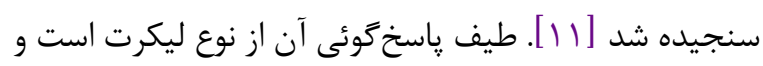

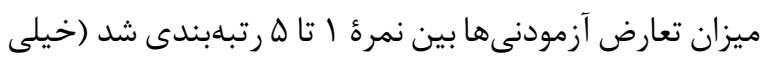

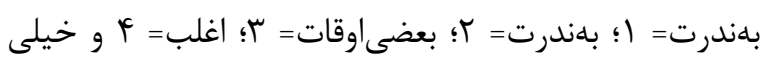

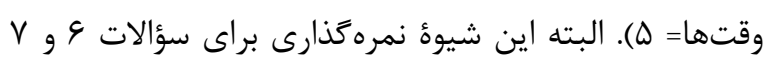

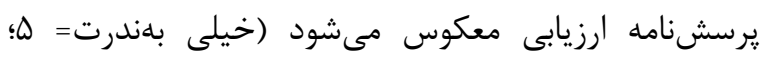

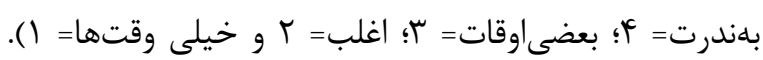
اين پرسشنامه داراى سه بُعد است كه زير مقياسهاى آن

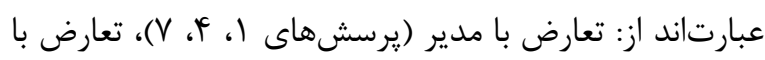

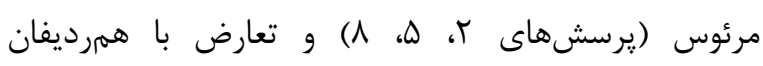

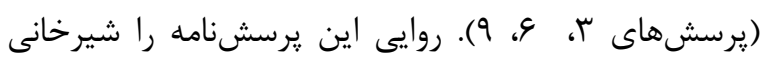

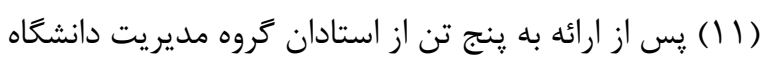

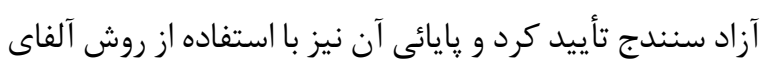

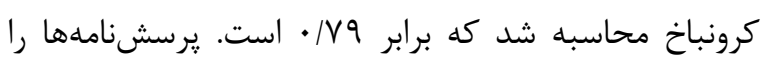

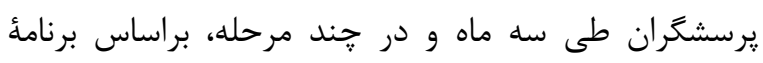

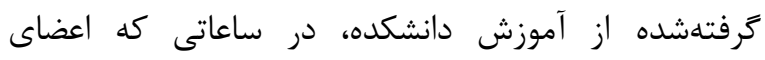

\begin{tabular}{|c|c|c|c|}
\hline درصد & ت تعداد & مشخصات دموكر افيك & \\
\hline fr & $\wedge \vee$ & زن & \multirow{2}{*}{ جنس } \\
\hline$\Delta \wedge$ & Ir. & مرد مرد & \\
\hline $11 / 9$ & rq & فوقليسانس & \multirow{2}{*}{ مدرك تحصيلى } \\
\hline $11 / 1$ & $19 \mathrm{~V}$ & دكترا & \\
\hline $9 / \pi$ & 11 & لِيمانى & \multirow{4}{*}{ نوع استخدام } \\
\hline$s 4 / T$ & ITF & رسمى & \\
\hline $11 / 9$ & r & رسمى آزمايشى & \\
\hline $\mid F / \Delta$ & rA & قراردادى & \\
\hline
\end{tabular}

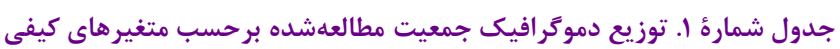


جدول شمارهُ r. توزيع ميانَين تعارض سازمانى و ابعاد سهَانئ آن و افسردَى در جامعةُ مطالعهشده

\begin{tabular}{|c|c|c|c|c|c|c|}
\hline انحراف معيار & ميانكَين & امتياز حداكثر & حداكثر امتياز قابل & امتياز حداقل & اكتسابل امتياز قابل & \\
\hline$r / \cdot r$ & s/V & 1 . & 10 & f & r & تعارض با مدير \\
\hline$|/ 4|$ & $V / f$ & 1. & 10 & 4 & r & تعارض با مرئوس \\
\hline • & $V / 9$ & 9 & 10 & V & r & تعارض با همرديفان \\
\hline r/AT & tr & rG & $i d$ & 11 & 9 & تعارض سازمانى \\
\hline$\cdot / V D$ & $\cdot \mid \Lambda$ & r & rI & · & . & افسردكى \\
\hline
\end{tabular}

نتايج يافتهها در جدول شماره f نشانگر وجود تأثير

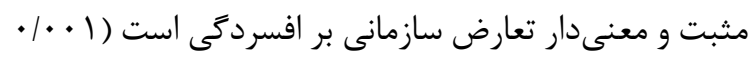

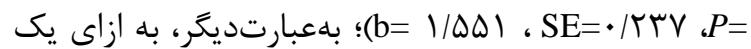
واحد افزايش در نمره تعارض سازمانى، نمرة افسردگى

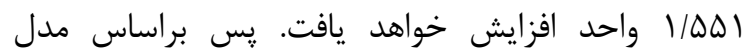

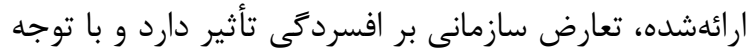
به يافتههاى حاصل از رگرسيون، اين تأثير فراوان است.

ضريب همبستخى بين افسردگى با تعارض سازمانى و ابعاد آن در جدول شماره ب آمده است. جدول شماره ץ نشان مى شهد كه بين تعارض سازمانى،

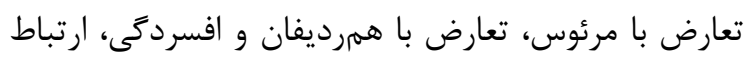

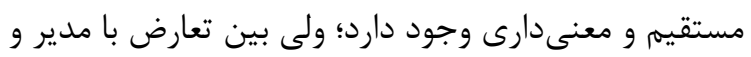
افسردگى ارتباط آمارى معنىدارى ديده نشد. بر همين

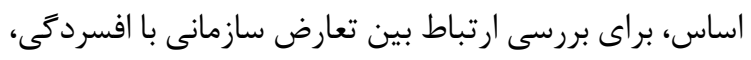

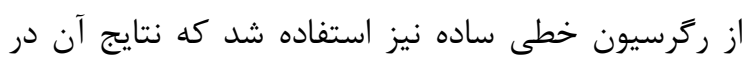
جدول شماره f آمده است.

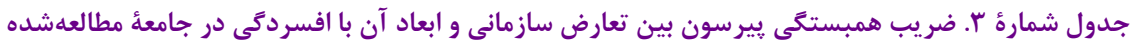

\begin{tabular}{|c|c|c|}
\hline \multicolumn{2}{|c|}{ افسردىى } & \\
\hline سطح معنى دارى & ضريب همبستكى يِيرسون & \\
\hline - NTY & $\cdot / \cdot r F$ & تعارض با مدير \\
\hline$\cdot 1 \cdot \cdot 1$ & - IFYA & تعارض با مرئوس \\
\hline$\cdot 1 \cdot \cdot 1$ &.$|9| \Delta$ & تعارض با همرديفان \\
\hline $.1 . .1$ & $\cdot / 410$ & تعارض سازمانى \\
\hline
\end{tabular}

جدول شمارؤ F. ضرايب ركَرسيون بين تعارض سازمانى با افسردكى در جامعهُ مطالعهشده

\begin{tabular}{|c|c|c|c|c|c|}
\hline \multirow{2}{*}{ Sig. } & \multirow{2}{*}{$\mathbf{T}$} & ضر ايب استاندارد & \multicolumn{2}{|c|}{ ضرايب غير استاندارد } & \\
\hline & & Beta & Std. Error & B & \\
\hline$\cdot 1 \cdots$ & $\vee ৭ / \vee \wedge \wedge$ & & $\cdot|r 4|$ & $r \cdot \mid \Lambda \varepsilon$. & \\
\hline$\cdot 1 \cdots$ & G/QDF &.$/ 410$ & . & $1 / \Delta Q 1$ & افسردكى \\
\hline
\end{tabular}

\section{بحث و نتيجه تَيرى}

و سابقه خدمت، با افسردگى ارتباط معنىدارى از لحاظ

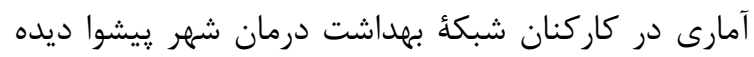
شد؛ ولى با سطح تحصيلات اين ارتباط مشاهده نشد [11] كه با نتايج اين مطالعه همخوانى دارد.
مقايسُٔ ميانگين نمرههاى افسردگى برحسب هر يك از

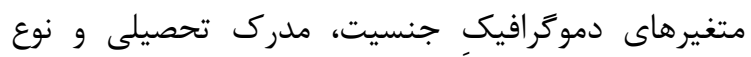

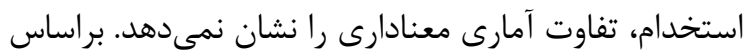
تحقيق نبى يور بين جنسيت (زن)، اعتقادات و تجارب دينى 
تعارض خانواده ـ كار، ميزان سلامت روان زنان شاغل كاهش

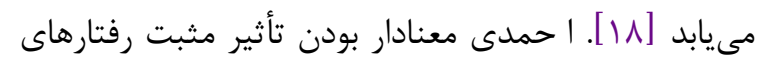

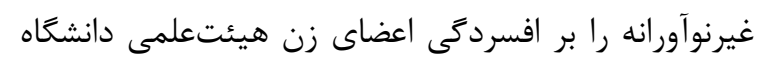

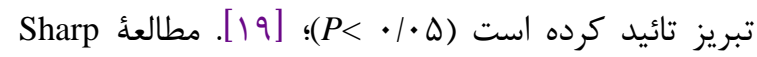

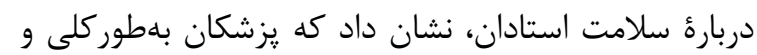

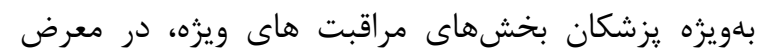

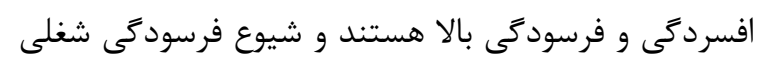

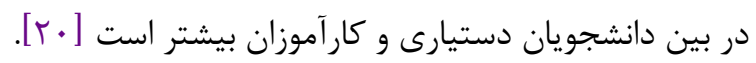

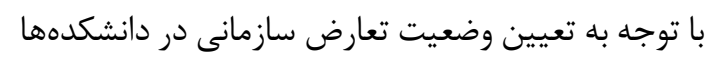

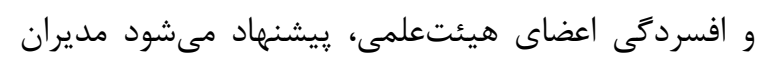

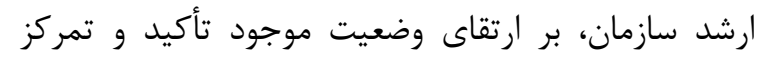

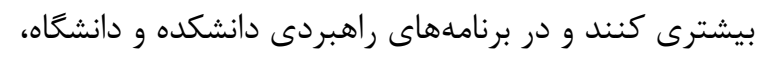

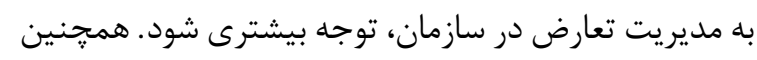

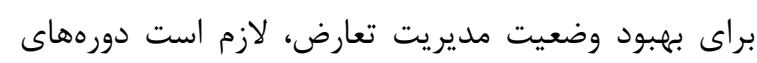

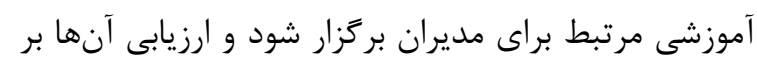

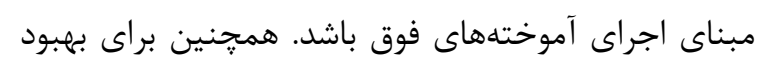

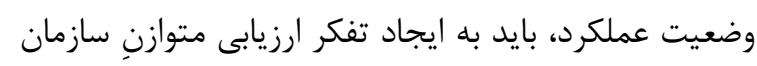

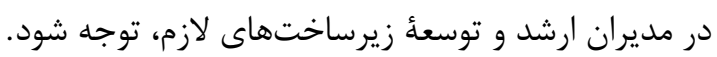

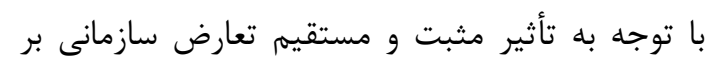

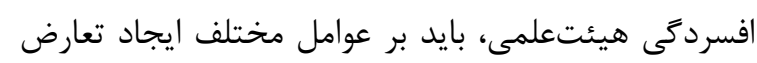

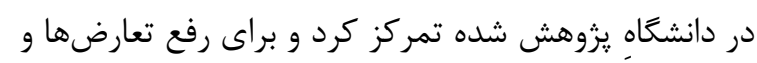

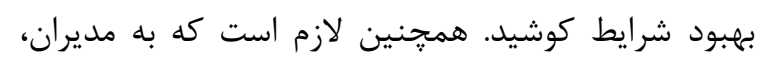

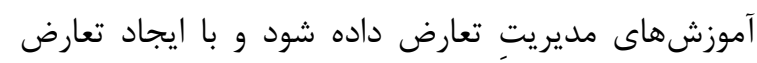

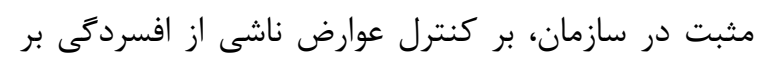

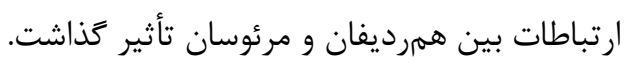

\section{تقدير و تشكر}

مطالعه حاضر بوسيله دانشخاه علوم يزشكى همدان در دار

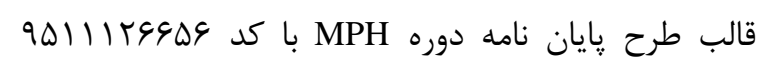

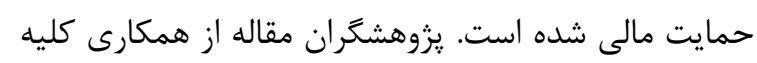

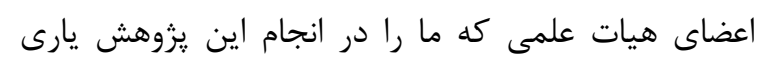

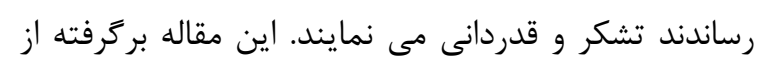

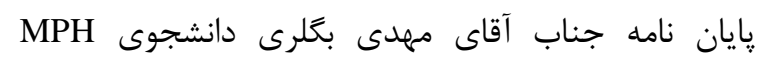

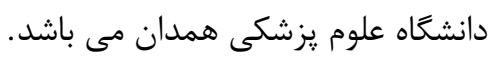

$$
\text { تعارض منافع }
$$

بين نويسندكان هيجَّونه تعارضى در منافع وجود ندارد
موسى رضائى وجود ارتباط آمارى معنى دارى بين

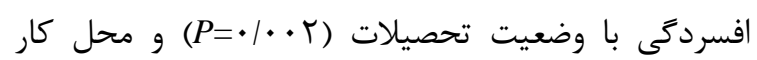

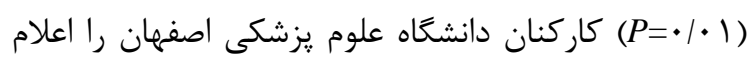

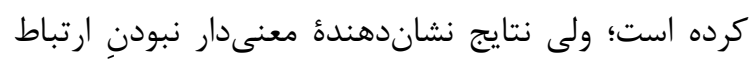

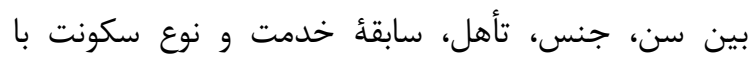

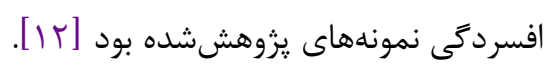

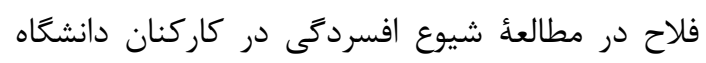
زنجان، ارتباط معنىدارى را بين افسردى مطى با متغيرهاى

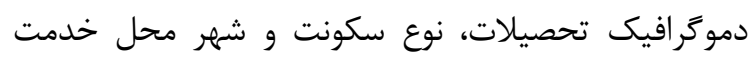

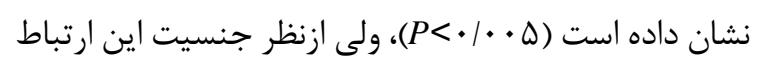

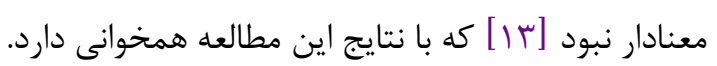

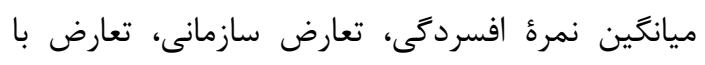

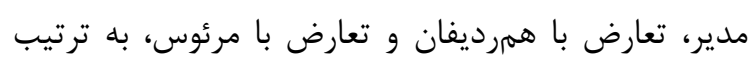

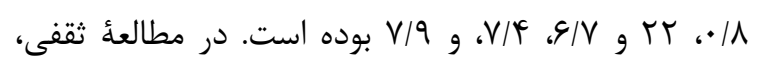
تعارض با مدير اهميت بيشترى دارد كه با نتايج اين مطالعه

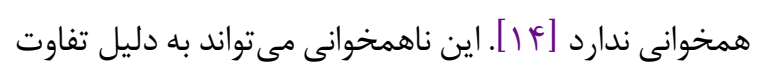

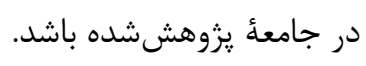

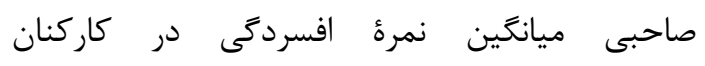

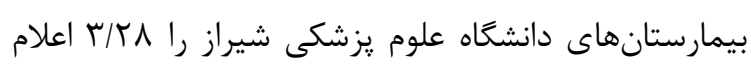

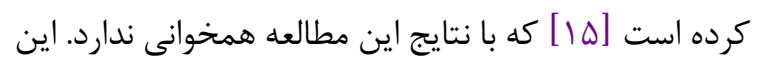

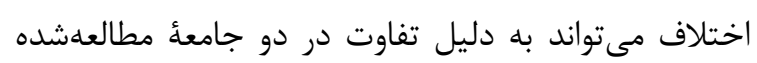
(كاركنان بيمارستانها و اعضاى هيئتعلمى) باشد.

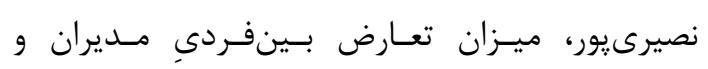

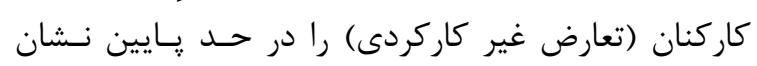

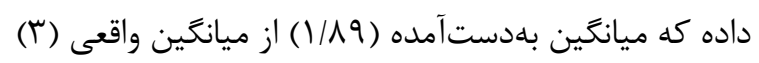

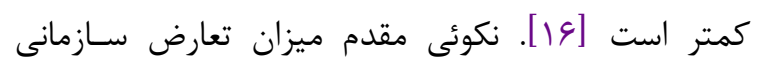

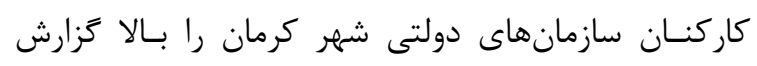
كرده است [IV] نتايج حاكى از وجود ارتباط مثبت و معنى معنى الرار بين

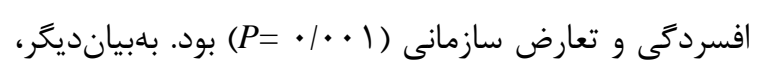

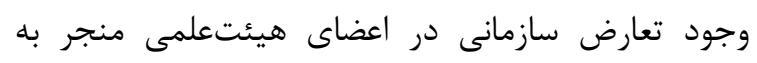

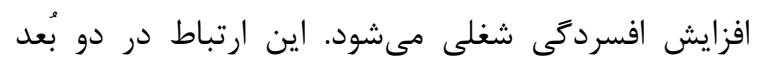

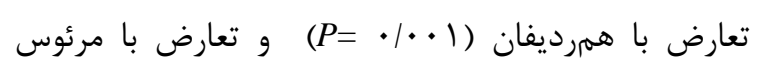

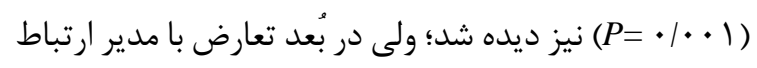

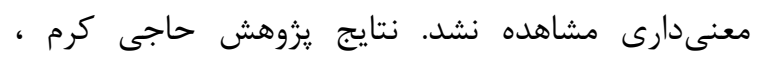

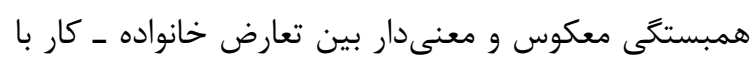

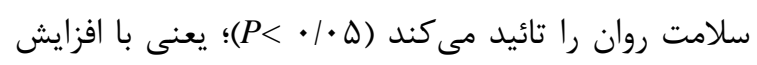




\section{References}

1. Ahmadi MS, Taghipour F, Farshi F. Investigating the Effect of Non-innovative Behaviors on the depression of the Female Academic Staff Members of Islamic Azad University-Tabriz Branch. Woman and Family Studies. 2014;6(23):31-43.

2. Salehi L, Solimanizadeh L, Bagheri Yazdi SA, Abbaszadeh A. The relationship between religious beliefs and locus of control with mental health. J Qazvin Univ Med Sci. 2007;11(1):1-10.

3. Kooshan M, Vaghei S. Mental health. Andishe rafie publisher. 24-26.

4. Hamidi Y, Mehri M, Zamanparvar A, Imani B. Relationship between managerial skills and employees job stress in health centers. J Res Health Sci. 2012;12(2):122-6. PMID: 23241525

5. Somers JM, Goldner EM, Waraich P, Hsu L. Prevalence and incidence studies of anxiety disorders: a systematic review of the literature. Can J Psychiatry. 2006;51(2):100-13. https://doi.org/10.1177/0706743706051002 06. PMID: 16989109

6. Robbins SP. Organizational Behavior, 13/E. Pearson Education India; 2009 Sep 1.

7. Ghafouriyan H, Falamarzi A. Relationship between Conflict and Job Performance. Journal of Modern Industrial/Organizational Psychology, 2010 (2);35-48

8. Mirkamali M. Manuscript and Human Relations, Faculty of Educational Sciences, Tehran University. 1987. p 61.

9. Miri A, Valavi P, heikh Azadi M. Comparative Study of Conflict Management from the Viewpoint of Islam and Other Scientific Schools. Islam \& Management, 2015; 3(6): 111138. Online research site, electronic version for all disciplines.WWW.SAPAIRAN.IR

10. Shirkhani H. Emotion with Organizational Conflict in Ilam City Bank Employees with Emphasis on Interpersonal Conflicts. Published at the National Conference on Entrepreneurship, Cooperatives, Economic Jihad in 2011. html.045_NCECEJ01-NCECEJ01-

Paper/com.civilica.

11. Prevalence of depression and its related factors in Pishva District Health Network employees in 2013. J Health Dev. 2014; 3 (4) :323-332

12. Musarezaie A, Momeni-Ghalehghasemi T, Musarezaie N, Moeini M, Khodaee M. Investigate the Prevalence of Depression and its association with Demographic variables in employees . IJPN. 2014; 2 (3) :37-45

13. Fallah R, Farhadi S, Amini K, Mohajeri M. Prevalence of Depression in Personnel of Zanjan University of Medical Sciences. zumsj. 2011; 19 (75) :107-113

14. Saqafi M, Moqadam Zadeh H. An investigation of the relationship of emotional intelligence with organizational conflicts of Birjand executive agencies' financial staffs with an emphasis on interpersonal conflicts. Journal of Fundamentals of Mental Health, 2017; 19(special issue): 56-65. doi: 10.22038/jfmh.2017.8627
15. Sahebi L, Ayatollahi M. Mental health status of hospitals staffs in Shiraz. Horizon Med Sci . 2007; 12 (4) :26-33

16. Nasiripour A., Riahi, L, Afzal E. The Relationship Between Communication System and Organizational Conflict at Hazrate Rassoul Hospital Tehran. , 2009; 20(83): 55-64.

17. Nekooei moghadam M, PirmoradBezanjani N. A Survey of the Relationship between Personality Characters and Organizational Conflict in Public Organizations. Iranian Public Administration, 2008; 0(1) PP 105 - 122. [Persian]

18. Hajikram A. Relationship between Family-Work with Mental Health and Marital Conflict in Women Employed in Tehran. Clinical research on psychology and counseling, 2016, 6 (1), pp. 113-127. [Persian] file:///C:/Users/a/Downloads/13756-209946-1PB.pdf

19. Ahmadi MS, Taghi Pourfarshi F. The Effect of Non-Innovative Behaviors on Depression in Female Faculty Members of Islamic Azad University, Tabriz Branch. Woman and Family Studies. 2014; 6(23):31-43.

20. Sharp M, Burkart KM. Trainee Wellness: Why It Matters, and How to Promote It. Ann Am Thorac Soc. 2017;14(4):505-12. https://doi.org/10.1513/AnnalsATS.201612 -1006PS. PMID: 28165295 